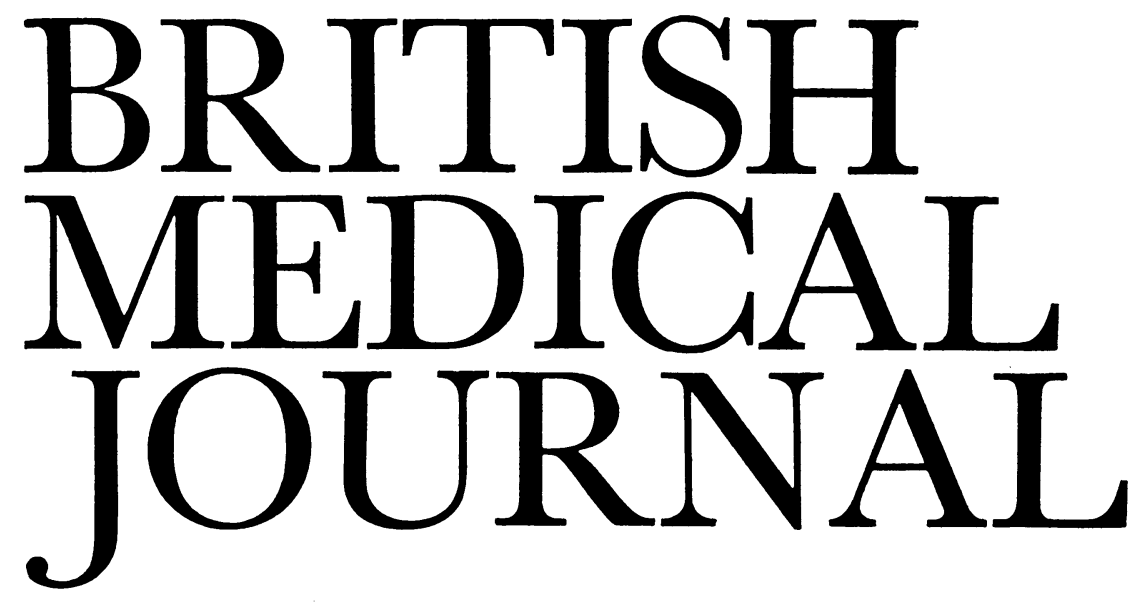

LONDON, SATURDAY 5 JUNE 1982

\title{
Sex hormones and gynaecological cancer
}

The opportunities for preventing cancer of the sex organs in women tend to be very different from those arising with other cancers $^{1}$ : for instance, avoidance of sexual intercourse would probably almost eliminate carcinoma of the cervix. ${ }^{2}$ Even, however, with the current fashion for extrauterine fertilisation coital abstinence will never become an acceptable prophylactic, but further research stimulated by the epidemiological findings may lead to more practicable approaches. ${ }^{3}$

With cancers of the breast, ovary, and endometrium sexual activity (in so far as it is measured by numbers of pregnancies) appears to be protective. The action may be hormonally mediated, and of these cancers endometrial carcinoma has the clearest endocrine relation: oestrogens unopposed by progestogens predispose to it, while progestogens can inhibit established tumours and may also act prophylactically. A recent report ${ }^{4}$ suggests that the progestogen in oral contraceptives may have such a protective effect; the numbers were small and analysis of the total data gave results that did not reach statistical significance, but the calculated relative risk of 0.44 is in keeping with other estimates. ${ }^{5}$ Apart from comparison with controls, the pattern of the data is persuasive: protection appears greater with use for over five years, with recent use, and with more progestogenic preparations. This last trend matches the observation that sequential oral contraceptives (in which only some of the tablets taken each month contain progestogen) have been associated with a higher incidence of endometrial cancer than combined preparations. ?

A cancer-prevention programme based on long-term manipulation of the "milieu intérieur" of a large proportion of the population would be socially unacceptable. Since, however, oral contraceptives produce such a change and are widely used, minor modifications of regimens should be examined in the hope of enhancing any cancer-inhibiting effect without increasing their adverse effects. The sequential regimen seems not to protect against endometrial cancer, while combined oestrogen and progestogen for 21 out of 28 days may give some protection; so daily progestogen alone may be more protective. It was only because regular menstruation was regarded as a natural phenomenon that the regimen for oral contraceptives was designed to simulate this pattern. In reality, given uninhibited sexual activity without contraception and uninhibited lactation after delivery, menstruation is rare. Manipulation of the female sexual cycle did not begin with Pincus and his pill: in the Western world cyclic menstruation became established as a consequence of adoption of Judaeo-Christian sexual mores.

The other adjustment of the internal environment in common use is hormonal replacement for postmenopausal women. Unopposed oestrogen has been found to increase the risk of endometrial cancer, but adding progestogen may counteract the effect. ${ }^{8}$ Possibly, a regimen with an optimal progestogen component might even reduce the incidence.

The endometrium and ovarian epithelium have common origins, and their cancers show epidemiological similarities. Cancer of the ovary seems to be less frequent in users of oral contraceptives, ${ }^{9-11}$ so women taking the pill may get some protection against both types of cancer. How large this effect may be for ovarian cancer is not clear, but any cut in its frequency is important because of the very high mortality.

An inevitable consequence of oral contraception is more coitus without barrier contraception, so that cervical cancer would be expected to be more common in women taking the pill. In practice, no evidence has emerged of a substantial increase in invasive tumours in pill users, ${ }^{112}$ though intraepithelial lesions are more common. Far from predisposing to gynaecological cancer, as was initially feared, oral contraceptives (or at least their progestogen component) seem to be having an overall favourable influence on the incidence of neoplasms.

Such a balance of risks and benefits is much more difficult to assess for cardiovascular effects, particularly as these are undergoing a worldwide reappraisal. ${ }^{13-16}$ Judgments on such issues, which come almost in the realm of medical philosophy, demand the combined wisdom of a whole sagacity of Solomons -yet the major decisions here have often been left to the Pharaohs of the pharmaceutical empires.

Inevitably any long-term change in the physiological state such as that produced with oral contraception and postmenopausal hormone replacement will result in a change in disease patterns. Thus the press has a responsibility to inform the public and to transmit the good news as well as the bad. Monitoring systems designed to detect adverse reactions to therapeutic agents are not adequate for assessing these effects. What we need are expanded record-linkage analyses of total morbidity and mortality for large populations, but these will take decades to complete, and even then the results will be confused through variables arising in the interval. Meantime women in reproductive and postmenopausal phases demand 
guidance; at present our advice must be based on the results of extended and refined short-term studies-blended with common sense.

Professor of Obstetrics and Gynaecology,

JAMES S SCOTT

Department of Obstetrics and Gynaecology

(Leeds Maternity Hospital),

Leeds LS2 9NG

1 Doll R, Peto R. The causes of cancer. Oxford: Oxford University Press, 1982 .

2 Beral V. Cancer of the cervix: a sexually transmitted infection ? Lancet $1974 ; \mathrm{i}: 1037-40$.

${ }^{3}$ Miller AB, Rawls WE. Epidemiology of gynecologic cancer: I. Cervix. In: Coppleson $\mathrm{M}$, ed. Gynaecologic oncology. Vol 1. Edinburgh: Churchill Livingstone, $1981: 9-18$.

${ }^{4}$ Hulka BS, Chambless LE, Kaufman DG, Fowler WC Jr, Greenberg BG. Protection against endometrial carcinoma by combination-product oral contraceptives. $\mathcal{F} A M A 1982 ; 247: 475-7$.

5 Weiss NS, Sayvetz TA. Incidence of endometrial cancer in relation to the use of oral contraceptives. N Engl F Med 1980;302:551-4.

6 Kaufman DW, Shapiro S, Slone D, et al. Decreased risk of endometrial cancer among oral-contraceptive users. N Englf $\mathrm{Med} 1980 ; 303: 1045-7$.

7 Cohen CJ, Deppe G. Endometrial carcinoma and oral contraceptive agents. Obstet Gynecol 1977;49:390-2.

${ }^{8}$ British Gynaecological Cancer Group. Oestrogen replacement and endometrial cancer. Lancet 1981 ; : 1359-60.

- Beral V, Fraser P, Chilvers C. Does pregnancy protect against ovarian cancer? Lancet 1978; i :1083-6, 7.

10 Casagrande JT, Louie EW, Pike MC, Roy S, Ross RK, Henderson BE. "Incessant ovulation" and ovarian cancer. Lancet 1979;ii:170-2, 3.

${ }^{11}$ Beral V. The epidemiology of ovarian cancer. In: Newman CE, Ford $\mathrm{CHJ}$, Jordan JA, eds. Ovarian cancer: proceedings of the international symposium on ovarian cancer, 24-25 September 1979, Birmingham. Oxford: Pergamon Press, 1980:29-38

12 WHO Scientific Group. Steroid contraception and the risk of neoplasia. WHO Tech Rep Ser 1978; No 619.

${ }^{13}$ Goldzieher JW. Oral contraceptive hazards-1981. Fertil Steril 1981 ;35 : 275-6.

14 Shearman RP. Oral contraceptives: where are the excess deaths ? Med $\mathcal{F}$ Aust 1981 ; : $698-700$.

15 Vessey MP. Oral contraceptives and cardiovascular disease : some questions and answers. $\mathrm{Br}$ Med $\mathcal{F} 1982 ; 284: 615-6$.

${ }^{16}$ Ryan KJ. Endometrial cancer, epidemiology, and medical practice. $\mathscr{f} A M A$ $1982 ; 247: 496$.

\section{Good and bad news for medical schools}

Renée Short's Social Services Committee has confirmed in its most recent report UGC Cuts and Medical Services ${ }^{1}$ what everybody except perhaps the Government and the Department of Health and Social Security already knew-that teaching, research, and service work in medical schools will be severely damaged by university cuts. ${ }^{2}{ }^{3}$ The committee has recommended that an extra $£ 5 \mathrm{~m}$ in $1982-3$ and a further $£ 5 \mathrm{~m}$ in 1983-4 should be made available to protect the teaching of clinical medicine. (A summary of the conclusions and recommendations of the report is published on $\mathrm{p}$ 1720.) Prompted at the press conference to launch the report into the stronger language that is her true métier, Mrs Short said that it was "scandalous" that the Government should let the medical schools be so damaged. Furthermore, when discussing the amounts needed to protect the medical schools we were "talking about peanuts." The strong support and clear recommendation of the committee will be welcomed by the medical schools.

The main Parliamentary function of the Social Services Committee is to keep a close eye on the elephantine DHSS, and this it has done. In both the report and at the press conference the DHSS was strongly criticised for not making clear to the rest of the Government and to the UGC what dire effects the cuts would have on medical education. It was also taken to task for not monitoring carefully the effects of the cuts. The Rt Hon David Ennals, a former Secretary of State for Health and Social Security, and a current member of the Social Services Committee, said that he found the lack of communication between the DHSS, the DES, and the UGC "really extraordinary." The implication was that if the DHSS had done its job and made the UGC aware of what the cuts would mean to medical education then the cuts would never have been made.

The committee estimates that if the Government does not take further action then about 300 clinical academic posts might be lost by 1983-4. Patient care, teaching, and research are all being seriously affected, and what most concerns the committee is that it is shortage specialties and poorer regions that are being most sererely damaged. In its report on medical education $^{4}$ the committee called specifically for the expansion of academic posts in such specialties as a means of encouraging their development. Yet in the present round of cuts it is these very specialties that are most vulnerable. The committee wants the DHSS, the UGC, and the universities to strive to ensure their protection-and so they should. Rightly, too, the committee is not enthusiastic about the NHS taking over lost university posts. No government money is saved if salaries are paid by the NHS rather than by the universities, and such a policy would inevitably mean a shift away from essential teaching and research.

While medical schools will be cheered by the support of the committee, they will, as described by Professor Payne last week (29 May, p 1636), continue to be depressed by the gap between the $4 \%$ salary increase for doctors teaching in medical schools and the average increase of $6 \%$ for NHS doctors $(29$ May, p 1656). Doctors who enter the medical schools already often suffer financially for the privilege, and if this small but important discrepancy is not righted medical schools will find it still harder to attract the most able and keep up standards. Again, we are discussing Mrs Short's "peanuts," and again the damage done is likely to be quite out of proportion to the money saved. Mrs Short's committee points out that the problems it describes "can be resolved relatively easily and cheaply." So they can, and we join the committee in urging the Government to do so.

1 Social Services Committee. UGC cuts and medical services. London: HMSO, 1982.

Walton J. An act of madness? Br Med $\mathcal{F} 1981$;282:1150-2.

${ }^{3}$ Smith R. The starving of the medical schools. Br Med f 1982;284:335-7.

Social Services Committee. Medical education with special reference to the number of doctors and the career structure in hospitals. London: HMSO, 1981.

\section{Creutzfeldt-Jakob disease}

Creutzfeldt-Jakob disease is one of the spongiform encephalopathies, a group which also includes kuru and scrapie. The disease is extremely rare: its incidence has been calculated as 0.09 per million population, though this figure may be an underestimate. Most cases occur sporadically, but occasional reports have appeared of affected families. The illness usually presents between the ages of 40 and 60 , the sexes being equally affected. Most patients show the clinically characteristic picture, but a few present atypically, often with a more chronic course. Some patients die within months of onset, while others survive for several years; the average duration of illness is about a year. 